\title{
Inflammatory pseudotumour of the mouth and maxilla
}

A W H Shek, P C Wu, N Samman

\begin{abstract}
Aim-To describe the clinicopathological and immunophenotypical findings of two cases of inflammatory pseudotumour in the oral cavity.

Methods and Results-The patients presented with a short history of swelling in the cheek and the maxilla respectively. Magnetic resonance imaging or computerised tomography scan showed space occupying lesions with infiltrative margins which were interpreted as aggressive malignant neoplasms. Histological examination showed fascicles of spindle cells in a background of chronic reactive inflammatory cells including plasma cells, typical of inflammatory pseudotumour. The spindle cells were positive for vimentin, smooth muscle actin and CD68, but were negative for follicular dendritic cell markers. The lymphocytes showed no light chain restriction.

Conclusions-Inflammatory pseudotumour in the oral cavity is completely benign and simple excision is curative. However, it may be confused with a malignant tumour on clinical and radiographic grounds, and histologically the appearances can also be misinterpreted as those of a more aggressive lesion. Its correct recognition by the surgical pathologist is important to avoid unnecessarily radical and potentially mutilating surgery.

(F Clin Pathol 1996;49:164-167)
\end{abstract}

Keywords: inflammatory pseudotumour, oral cavity, immunohistochemistry.

Inflammatory pseudotumour is a tumour-like lesion characterised histologically by fascicles of plump spindle cells in a background of chronic inflammatory cells, notably plasma cells. Other synonyms have been used to describe similar lesions, such as plasma cell granuloma, histiocytoma, xanthomatous granuloma, inflammatory myofibroblastictumour, and spindle cell pseudotumour.

Inflammatory pseudotumour occurs in a wide variety of somatic tissue and visceral organs, including the lung, ${ }^{1}$ liver, ${ }^{2}$ thyroid ${ }^{3}$ and many other organs. Recently it has been described in the major salivary glands ${ }^{4}$ and the buccal tissue in children. ${ }^{5}$ We describe here the clinical, radiological, histological, and immunophenotypical findings of two examples of inflammatory pseudotumour in the oral cavity in adults.

\section{Case reports}

CASE 1

A 20 year old man was referred for a swelling over the right cheek. This had been present for one month and did not respond to antibiotic treatment. Physical examination revealed a diffuse swelling over the right cheek. Intraorally, there was a firm exophytic mass of $2 \mathrm{~cm}$ diameter in the right cheek opposite the molar region. The overlying mucosa was ulcerated, but there was no discharge. Magnetic resonance imaging (MRI) revealed an infiltrative lesion invading skin and parotid duct (fig 1). The impression was that of an aggressive neoplasm.

Fine needle aspiration was performed and smears showed non-specific chronic inflammation with epithelioid-like cells present (fig 2). Special stains for micro-organisms, including mycobacteria and fungi, were negative. Excisional biopsy was advised.

The lesion was completely excised and histological examination showed fascicles of elongated spindle cells in a mixed inflammatory background with a predominance of plasma cells (fig 3). Special stains for micro-organisms, including mycobacteria and fungi, were negative. The majority of the spindle cells were positive for CD68 (Dako) and vimentin (Dako), while a smaller number were positive for smooth muscle actin (BioGenex), but they were negative for $\mathrm{S}-100$ (Dako), MAK-6 (Ciba), CD21 (Dako), Ber-MAC-DRC (Dako), and Ki-M4 (table 1). The lympho-

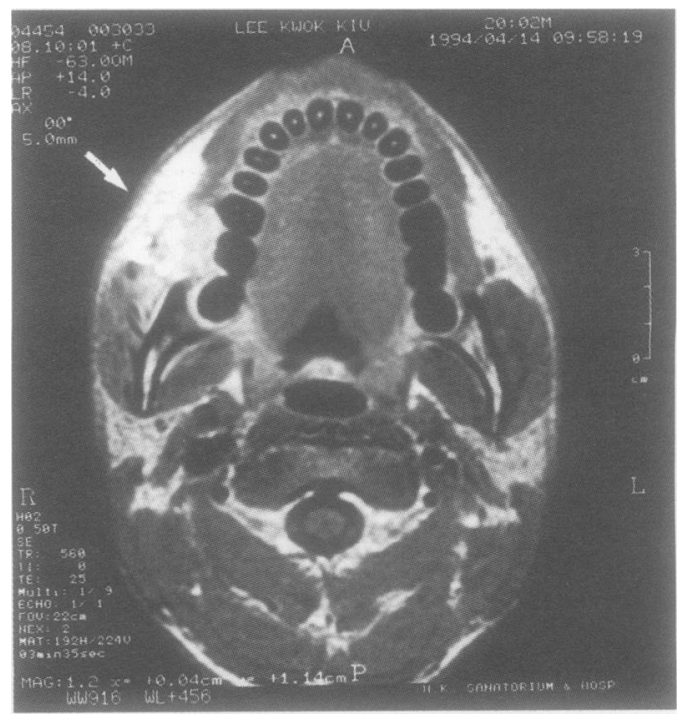

Figure 1 MRI appearance of the firm indurated mass (arrow) anterior to the right masseter muscle, infiltrating skin but not involving bone.

University of Hong

Hospital, Hong Kong:

Pathology

Department of Ora
} 


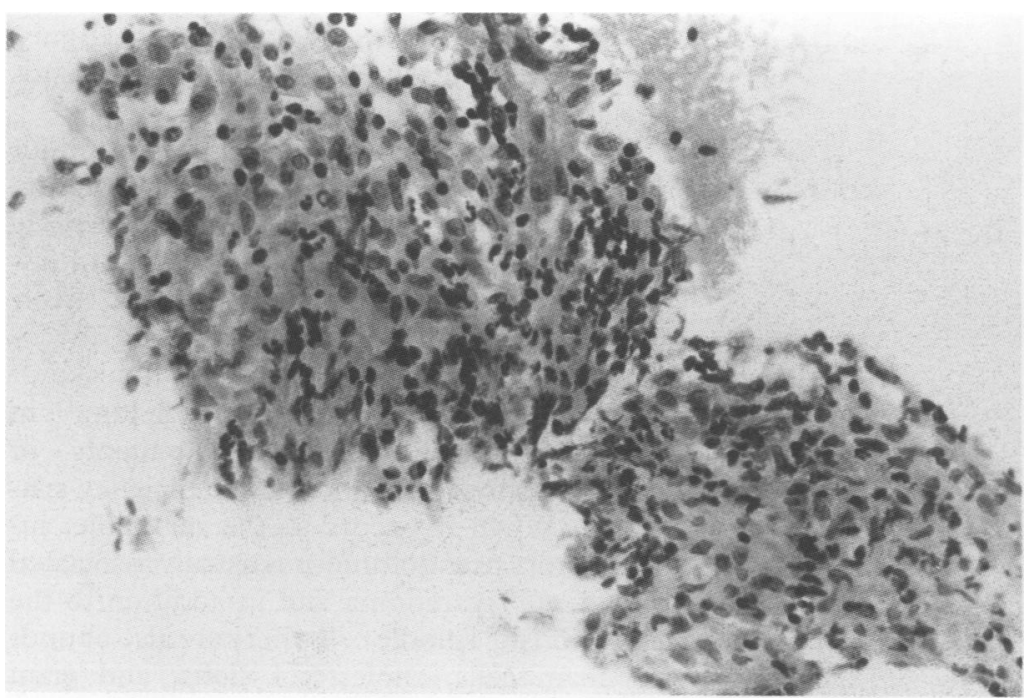

Figure 2 Clusters of mixed chronic inflammatory cells composed of histiocytes, lymphocytes, plasma cells, and some epithelioid cells $(\times 35)$.

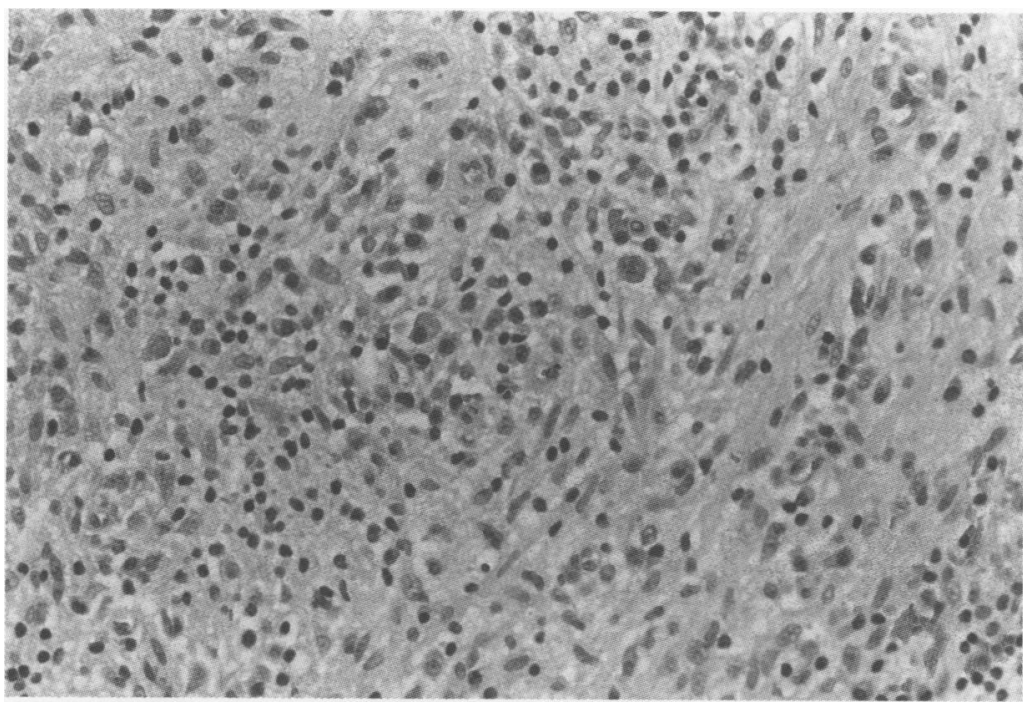

Figure 3 Short, swirling fascicles of spindle cells admixed with plasma cells and lymphocytes $(\times 114)$.

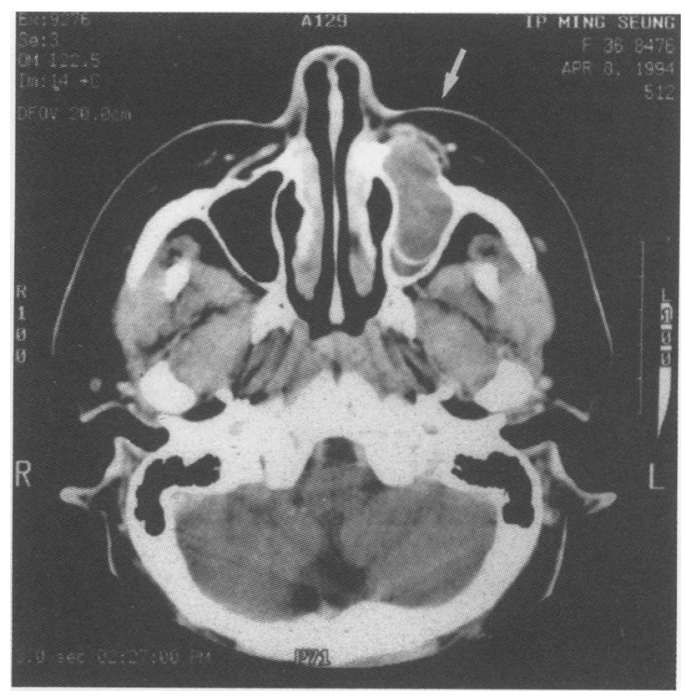

Figure 4 CT appearance of cystic lesion within the left maxillary sinus, with erosion of the anterior wall of the maxilla (arrow).

mal overlying skin. The eye movements were normal. No epiphora or nasal discharge was noted.

Intraorally, a diffuse swelling in the left upper buccal sulcus was present, extending from the midline to the maxillary tuberosity. The covering mucosa was normal. The second premolar was tender to percussion but both premolars and the first molar on the left side were negative to electric pulp testing. Plain radiographs showed a loculated cystic lesion in proximity to the left maxillary teeth and extending into the left maxillary sinus. There was no root resorption. Computed tomography (CT) scan showed a cystic lesion occupying a large part of the maxillary sinus with evidence of erosion of the anterior wall of the sinus in the infraorbital region (fig 4). It was interpreted as an aggressive neoplasm.

Open biopsy through an intraoral sulcus incision revealed a cystic cavity containing straw coloured fluid with an irregular yellowish firm mass at its wall on the cheek. Histological examination showed fibroblastic spindle cells admixed with abundant chronic inflammatory cells and focally the stroma was loose and myxoid, closely resembling that of nodular fasciitis (fig 5). The lesion was entirely resected. Microscopic examination showed fascicles of plump spindle cells with abundant plasma cells and lymphocytes in the background, identical with that of case 1 . Areas resembling nodular fasciitis found in the previous biopsy specimen

A 36 year old woman was referred for management of a painless, gradually enlarging swelling in the left maxilla for the past year. Physical examination revealed a small palpable swelling in the left infraorbital region with nor-

Table 1 Immunohistochemical profiles of the spindle cells in the two cases of inflammatory pseudotumour

\begin{tabular}{lllll}
\hline Antibody & Source & Major reactivity & Results \\
\hline Smooth muscle actin & BioGenex (San Ramon, CA, USA) & Smooth muscle cell & Case 1 & Case 2 \\
CD68 & Dako (Glostrup, Denmark) & Histiocytes & $+(\mathrm{f})$ & + \\
Vimentin & Dako & Mesenchymal cells & + & $+(\mathrm{f})$ \\
S-100 & Dako & Interdigitating cells, & - & + \\
MAK-6 & Ciba (Alamendo, CA, USA) & melanocytic cells, etc & - & - \\
CD21 & Dako & Follicular cells & - \\
Ber-MAC-DRC & Dako & Follicular dendritic cell & - & - \\
Ki-M4 & $*$ & Follicular dendritic cell & - & - \\
\hline
\end{tabular}

$(f)=$ focally positive

* Kindly donated by Prof M R Parwaresch, Kiel, Germany. 


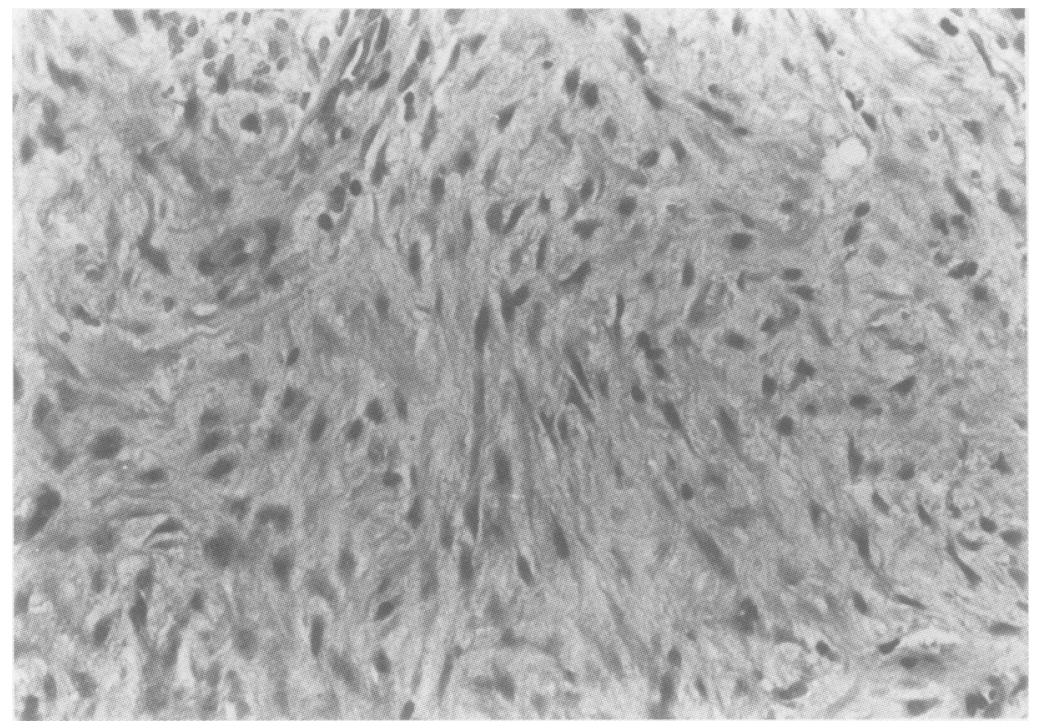

Figure 5 Spindle cells in a myxoid background, resembling nodular fasciitis $(\times 240)$.

were not seen. Special stains for microorganisms, including mycobacteria and fungi, were negative. The majority of these plump spindle cells stained strongly for vimentin and smooth muscle actin and only a minority was positive for $\mathrm{CD} 68$. They were negative for S-100, MAK-6, CD21, Ber-MAC-DRC, and Ki-M4 (table 1). Scattered CD68 positive macrophages were found among the chronic inflammatory cells. The plasma cells and lymphocytes showed no light chain restriction. The cyst was lined by ulcerated, non-keratinised, stratified squamous epithelium with a fibrotic wall, consistent with an infected residual cyst.

The patient was well at 13 months follow up with no recurrence of tumour.

\section{Discussion}

Inflammatory pseudotumour of the oral cavity is very rare and only eight previous reported cases are to be found in English language publications (table 2). It occurs in a wide age range (19 months to 63 years), but it tends to affect children and young adults. The cheek and the mandible are the sites of predilection. It presents as an intraoral painless swelling of relative short duration, which is firm and indurated on physical examination. Unlike its counterpart in the visceral organs, oral inflammatory pseudotumour does not produce significant systemic symptoms, and routine blood investigations are normal. Magnetic resonance imaging or a CT scan was done in two of the reported cases and in both of our patients.
All were characterised by infiltrative margins, and were interpreted on radiological grounds as aggressive malignant neoplasms.

The cause of inflammatory pseudotumour remains unknown and microbiological culture result is usually negative although Escherichia coli has been found in an example of inflammatory pseudotumour of the liver. ${ }^{11}$ Morphologically similar lesions caused by mycobacteria have been described in the skin, ${ }^{12}$ lymph node ${ }^{13}$ bone marrow, ${ }^{14}$ and lung $^{15}$ in immunosuppressed transplant patients or patients with acquired immunodeficiency syndrome. When it occurs in the mandible, inflammatory pseudotumour is usually associated with dental granuloma and in addition to the characteristic spindle cells there are also abundant foam cells, cholesterol clefts, and giant cells. ${ }^{67}$ Such concomitant presence of dental granuloma and a chronically inflamed cyst in our case 2 may lend support to the idea that inflammatory pseudotumour is an unusual tissue reaction to chronic inflammation.

Histologically, inflammatory pseudotumour of the oral cavity is similar to that of other organs, although a nodular fasciitis-like area has never been described. The proportion of spindle cells, foam cells, lymphocytes, and plasma cells is highly variable, and Chen ${ }^{16}$ reported an increased proportion of foam cells in a subsequent follow up biopsy specimen in a case of inflammatory pseudotumour of the liver. Furthermore the immunophenotype of the spindle cells is also highly variable; the plump spindle cells in case 2 were strongly positive for vimentin and smooth muscle actin but only weakly and sparingly positive for CD68, while in case 1 they were strongly positive for CD68 and weakly positive for smooth muscle actin and vimentin. This observation is consistent with the concept that these spindle cells are of fibrohistiocytic nature, showing the immunohistochemical phenotypes of both histiocytes and myofibroblasts. ${ }^{17} \mathrm{~A}$ similar observation has also been reported in inflammatory pseudotumours of the major salivary gland ${ }^{4}$ and the liver. ${ }^{2}$ The spindle cells in case 1 were more elongated and appeared epithelioid, which raises the possibility of granulomatous inflammation in cytological preparations. The cytological features of inflammatory pseudotumour have been described rarely. ${ }^{18} 19$ It is generally accepted that a definite cytological diagnosis of inflammatory pseudotumour cannot be made by fine needle aspiration cytology because the predominant cell pattern is non-specific. ${ }^{18}$

Table 2 Summary of reported cases of oral inflammatory pseudotumour

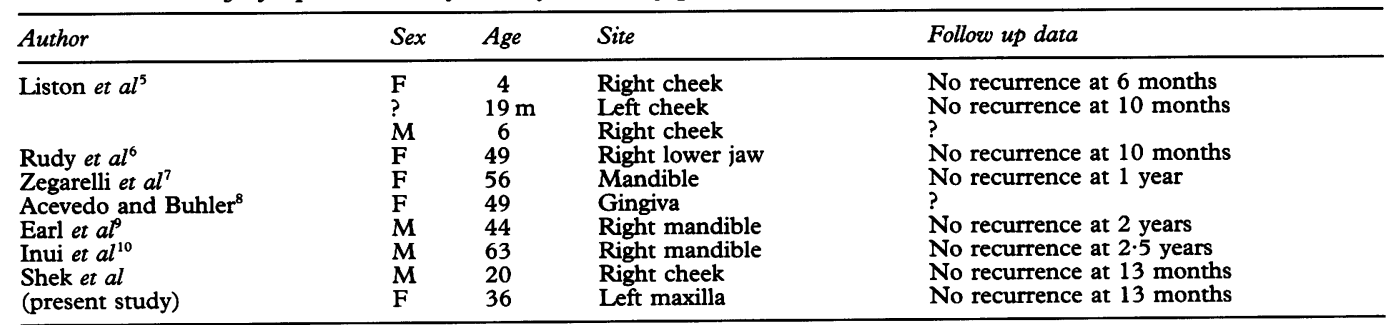


Being a fibrohistiocytic lesion, inflammatory pseudotumour may be misinterpreted by the histopathologist as being a neoplastic or quasineoplastic condition of the myofibroblasts, such as nodular fasciitis, fibromatosis, or fibrosarcoma. The positive immunohistochemical stain for actin in inflammatory pseudotumour can be a potential diagnostic pitfall and it may be mistaken as a leiomyosarcoma. Oral inflammatory pseudotumour needs to be distinguished from the recently described follicular dendritic cell tumour of the oral cavity, ${ }^{20}$ which runs an indolent course with a tendency of local recurrence. Nodular fasciitis uncommonly occurs in the oral cavity and it is characterised histologically by the presence of loose myxoid matrix containing short linear curved fascicles of spindle cells. ${ }^{2122}$ Although focal nodular fasciitis-like area was detected in case 2 , inflammatory pseudotumour can be distinguished by the presence of longer fascicles of spindle cells in an inflammatory background rich in plasma cells. Fibromatosis of the oral cavity usually occurs in young adults and it is characterised histologically by broad interlacing fascicles of mature fibroblasts with a variable degree of collagenisation. ${ }^{23}$ An inflammatory component is absent. It is notoriously difficult to separate fibromatosis from well differentiated fibrosarcoma, especially in infants and juveniles in whom fibromatoses are characterised by higher mitotic rates than in adults. Its distinction from inflammatory pseudotumour can be established by the absence of an inflammatory component. Follicular dendritic cell tumour of the oral cavity is a recently described entity which can closely mimic inflammatory pseudotumour, with whorls or fascicles of plump spindle cells in an inflammatory background of lymphocytes and histiocytes. ${ }^{20}$ In contrast, plasma cells constitute a significant proportion of the chronic inflammatory cells in inflammatory pseudotumour. The distinction can be established by the positive staining for CD21, Ber-MAC-DRC, and $\mathrm{Ki}-\mathrm{M} 4$ in follicular dendritic cell tumour. ${ }^{20}$

In conclusion, inflammatory pseudotumour of the oral cavity is a distinct pathological entity characterised by fascicles of spindle cells in an inflammatory background rich in plasma cells. Clinically and radiographically it may be misinterpreted as a malignant neoplasm. Cytologic diagnosis on fine needle aspiration can rarely reach a definitive diagnosis and excisional biopsy is usually required. Treatment is complete surgical resection which is curative. No death has been ascribed to it when it occurs in the oral cavity. Its correct recognition by surgical pathologists is, therefore, vital in order to avoid unnecessary extensive and radical surgery.

We would like to thank Prof MR Marwaresch for giving us the monoclonal antibody $\mathrm{Ki}-\mathrm{M} 4$.

1 Pettinato G, Manivel JC, DeRosa N, Dehner LP. Inflammatory myofibroblastic tumor (plasma cell granuloma). Clinicopathologic study of 20 cases with immunohistochemical and ultrastructural observations. Am f Clin Pathol 1990;94:538-46.

2 Shek TWH, Ng IOL, Chan KW. Inflammatory pseudotumor of the liver. Am $\mathcal{f}$ Surg Pathol 1993;17:231-8.

3 Chan KW, Poon GP, Choi CH. Plasma cell granuloma of the thyroid. F Clin Pathol 1986;39:1105-7.

4 Williams SB, Foss RD, Ellis GL. Inflammatory pseudotumors of the major salivary glands. Am $\mathcal{f}$ Surg Pathol 1992;16:896-902.

5 Liston SL, Dehner LP, Jarvis CW, Pitzele C, Huseby TL. Infammatory pseudotumors in the buccal tissues of chil-

6 Rudy HN, Conn H, Scheingold SS. Solitary xanthogranuloma of the mandible. Oral Surg Oral Med Oral Pathol 1964;18:262-71.

7 Zegarelli DJ, Rankow RM, Zegavelli EV. A large dental granuloma (?inflammatory pseudotumor) with unusual granuloma (?inflammatory pseudotumor) with unusual

8 Acevedo A, Buhler JE. Plasma cell granuloma of the gingiva. Oral Surg Oral Med Oral Pathol 1977;43:196-200.

9 Earl PD, Lowry JC, Sloan P. Intraoral inflammatory pseudotumor. Oral Surg Oral Med Oral Pathol 1993;76:279-83.

10 Inui M, Tagara T, Mori A, Yoneda J, Nomura J, Fukumori $\mathrm{T}$, et al. Inflammatory pseudotumor in the submandibular region. Clinicopathologic study and review of the litregion. Clinicol Sar Oral Med Oral Pathol 1993;76:333-7.

1 Standifo tandiford SB, Sobel H, Dasmahapatra KS. Inflammatory pseudotumor of the liver. F Surg Oncol 1989;40:283-7.

12 Woods C, Mickoloff BJ, Todes-Taylor NR. Pseudotumor resulting from atypical mycobacterial infection: a "histoid" variety of mycobacteria avium-intracellulare complex infection. Am ₹ Clin Pathol 1985;85:524-7.

13 Chen KTK. Mycobacterial spindle cell pseudotumor of lymph nodes. Am $\mathcal{F}$ Surg Pathol 1992;16:276-81.

14 Ulmas J, Federman M, Crawford C, O'Hara BAC, Fitzgibbons J, Modeste A. Spindle cell pseudotumor due to Mycobacterium avium-intracellulare in patients with acquired immunodeficiency syndrome (AIDS): posi staining of mycobacteria for cytoskeleton filaments. $A m \mathcal{F}$ staining of mycobacteria for
Surg Pathol 1991;15:1181-7.

15 Sekosan M, Cleto M, Senseng C, Farolan M, Sekosan J. Spindle cell pseudotumors in lungs due to Mycobacterium tuberculosis in a transplant patient. Am $\mathcal{F}$ Surg Pathol 1994;18:1065-8.

16 Chen KTK. Inflammatory pseudotumor of the liver. Hum Pathol 1984;15:694-6.

17 Facchetti F, De Wool Peeters C, De Wever I, Frizzera G. Inflammatory pseudotumor of lymph nodes. Immunohistochemical evidence for its fibrohistiocytic nature. Am 7 Pathol 1990;137:281-9.

18 Thunnissen FBJM, Arends JW, Buchholtz RTF, ten Velde $G$. Fine needle aspiration cytology of inflammatory pseudotumor of the lung (plasma cell granuloma). Report pseudotumor of the lung (plasma cell gran

19 Usuda K, Saito Y, Imai T, Ota S, Sato M, Fujimura S, et al. Inflammatory pseudotumor of the lung diagnosed as granulomatous lesion by preoperative brushing cytology. A case report. Acta Cytol 1990;34:685-9.

20 Chan JKC, Tsang WYW, Ng CS, Tang SK, Yu HC, Lee AWM. Follicular dendritic cell tumors of the oral cavity. Am F Surg Pathol 1994;18:148-57.

21 Davies HT, Bradley N, Bowerman JE. Oral nodular fasciitis. Br f Oral Maxillofac Surg1989;27:147-51.

22 Werning JT. Nodular fasciitis of the orofacial region. Oral Surg 1979;18:441-6.

23 Vally IM, Altini $M$. Fibromatosis of the oral and paraoral soft tissue and jaws. Oral Surg Oral Med Oral Pathol 1991; 69:191-8. 